\title{
Rescue therapy for acute idiopathic thrombocytopenic purpura unresponsive to conventional treatment
}

\author{
Samuel Benjamin Reynolds, ${ }^{1}$ Hamza Hashmi, ${ }^{2}$ Phuong Ngo, ${ }^{2}$ Goetz Kloecker $^{2}$
}

'Department of Internal

Medicine, University of Louisville School of Medicine, Louisville, Kentucky, USA

${ }^{2}$ Department of HematologyOncology, Louisville School of Medicine, Louisville, Kentucky, USA

\section{Correspondence to}

Dr Samuel Benjamin Reynolds, samuel.reynolds@louisville.edu

Accepted 3 December 2018

Check for updates

(C) BMJ Publishing Group Limited 2019. No commercial re-use. See rights and permissions. Published by BMJ.

To cite: Reynolds SB, Hashmi H, Ngo P, et al. BMJ Case Rep 2019;12:e227717. doi:10.1136/bcr-2018227717

\section{SUMMARY}

A 61-year-old woman with chronic lymphocytic leukaemia, with Richter's transformation to a diffuse, large, B-cell lymphoma, treated with six cycles of rituximab, cyclophosphamide, doxorubicin, vincristine and prednisone and in complete remission, presented to the hospital after her platelets were found to be $2 \times 10^{3} / \mu \mathrm{L}$ in outpatient laboratory studies. She initially underwent a platelet transfusion without improvement. This was followed by 4 days of high-dose dexamethasone and intravenous immunoglobulin, which again yielded no meaningful effect. Even a single-dose rituximab failed to achieve a platelet increase after 5 days of monitoring. The patient was then given $2 \mathrm{mg}$ of intravenous vincristine along with a high-dose of dexamethasone and IVIG and demonstrated substantial recovery in platelets to $>50 \times 10^{3} / \mu \mathrm{L}$ within 48 hours. This case study provides an overview of the current management strategies for idiopathic thrombocytopenic purpura that is unresponsive to conventional medical therapy and particularly sheds light on their therapeutic benefits and potential adverse effects.

\section{BACKGROUND}

The initial management of idiopathic thrombocytopenic purpura (ITP) with steroids or intravenous immunoglobulin in the setting of life-threatening bleeding or platelet count $<5-10 \times 10^{9} / \mathrm{L}$ is well established in literature. Less known, however, is the management of ITP that fails to respond to initial rescue therapy with steroids and intravenous immunoglobulin combination. We present a case of ITP that failed to respond to the initial treatment with steroids and intravenous immunoglobulin, but responded well to a combination of vincristine, steroids and IVIG. The management of ITP that has failed to respond to the conventional therapy is an often discussed, but poorly understood concept. So, the learning points set forth in this report, we hope, will serve as a valuable tool for haematologists in bettering the care of their patients.

\section{CASE PRESENTATION}

We present the case of a 61-year-old woman who was diagnosed with chronic lymphocytic leukaemia (CLL) in routine laboratory studies. She was relatively asymptomatic from her CLL and did not meet any indications for treatment and was under observation only. Two years after her initial diagnosis, she developed right upper-quadrant abdominal pain and the CT of the abdomen and pelvis revealed a
$5.5 \times 6.2 \mathrm{~cm}$ hypodense mass in the liver hilum with central necrosis, extending along the course of the common bile duct and displacing both the hepatic artery and portal vein anteriorly. It was inseparable radiographically from the pancreatic head.

Biopsy of the mass revealed diffuse, large B-cell lymphoma in the background of small lymphocytic lymphoma, confirming Richter's transformation. The patient received 6 cycles of rituximab, cyclophosphamide, doxorubicin, vincristine and prednisone - and achieved complete remission. She was doing well and had no evidence of disease relapse for 3 years until she presented to her primary physician with complaints of easy bruising and epistaxis of 2 weeks' duration. Physical examination was significant for ecchymoses on the upper and lower extremities. On laboratory evaluation, she was found to have a platelet count of $2 \times 10^{9} / \mathrm{L}$, white cell count of $6.7 \times 10^{9} / \mathrm{L}$ and haemoglobin of $139 \mathrm{~g} / \mathrm{L}$. Peripheral smear did not reveal any evidence of platelet clumping, schistocytes or blasts. CT of the chest, abdomen and pelvis showed no lymphadenopathy or haepatosplenomegaly. The patient was admitted to the hospital for further workup and treatment of symptomatic thrombocytopenia.

Upon admission, she was transfused 4 units of platelets with no significant change in her platelet count. She was started on oral dexamethasone $40 \mathrm{mg}$ daily and after two days of high-dose steroids, her platelet count was still $2 \times 10^{3} / \mu \mathrm{L}$. She then received intravenous immunoglobulin $(1 \mathrm{~g} / \mathrm{kg} / \mathrm{day})$ for 2 consecutive days. Unfortunately, her platelet count remained low at $2 \times 10^{3} / \mu \mathrm{L}$ after finishing pulse therapy with 2 days of intravenous immunoglobulin and 4 days of dexamethasone.

At this time, a bone marrow biopsy was performed revealing 40\%-50\% total marrow cellularity with adequate trilineage haematopoiesis and 30\%-40\% involvement with an abnormal B-cell population. This abnormal population was identified by flow cytometry as being positive for CD5, CD19 and CD23 with dim surface kappa light chain restriction, consistent with CLL. Fluorescence in situ hybridization (FISH) analysis was significant for deletion of ATM locus at 11q22 and deletion $13 \mathrm{q}$ and negative for deletion p53 and trisomy 12 .

On hospital-day 7 , she received a single dose of rituximab at $375 \mathrm{mg} / \mathrm{m}^{2}$, but her platelet count remained low at approximately $2-3 \times 10^{9} / \mathrm{L}$ for the next 5 days. Her clinical course was further complicated by the development of spontaneous epistaxis and wet purpura in the oral mucosa. At this time, she was given a single dose of $2 \mathrm{mg}$ of IV vincristine 


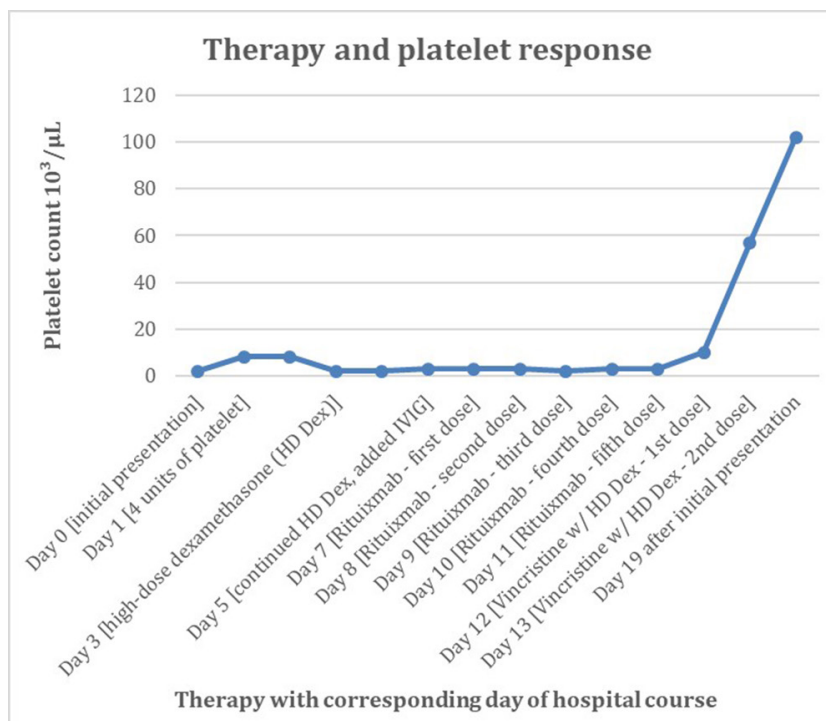

Figure 1 Response in platelet number by therapy. Note that platelet count was, on initial presentation, $2 \times 10^{9} / \mathrm{L}$ and remained at this value for 12-14 days, despite the addition of rituximab. Not until vincristine and re-administration of steroid and intravenous immunoglobulin, was a substantial recovery in platelet count observed.

along with a second pulse dose of high-dose dexamethasone and IVIG. Within 24 hours of initiating this treatment, her platelet count improved to $10 \times 10^{9} / \mathrm{L}$, and within 48 hours, it was $57 \times 10^{9} / \mathrm{L}$. She was discharged home and, approximately 1 week later, her platelet count continued to show improvement to $102 \times 10^{9} / \mathrm{L}$. Given recurrence of CLL, upon follow-up clinic visit, she was started on a systemic chemotherapy with combination of cyclophosphamide, vincristine and prednisone (CVP). A summary of treatment is shown in figure 1.

\section{INVESTIGATIONS}

There were no imaging studies performed for this patient, but she did undergo a bone marrow biopsy with subsequent flow cytometry, which, as stated above in the case description, was positive for CD5, CD19 and CD23 with dim surface kappa light chain restriction. FISH analysis then revealed deletion of ATM locus at $11 \mathrm{q} 22$ and deletion $13 \mathrm{q}$, but with no deletion of p53 nor trisomy 12 .

\section{DIFFERENTIAL DIAGNOSIS}

This is not relevant to this case as the diagnosis was easily made and recognised. The more unique aspect of this case is patient management.

\section{TREATMENT}

Treatment is relevant and is detailed in the case description above.

\section{OUTCOME AND FOLLOW-UP}

The main outcome for the patient was a quantitative recovery in platelets with no evidence of continued bleeding. On immediate follow-up, the patient was started on systemic chemotherapy, as mentioned above, with a combination of CVP. This regimen was well-tolerated by the patient, and her disease has not recurred since (now almost 4 months after treatment). She continues to follow-up regularly with her medical oncologist who has not found her platelets to be outside the normal range since her aforementioned hospitalisation.

\section{DISCUSSION}

The incidence of ITP is approximately 3.3 per 100000 adults. ${ }^{1}$ The disease is generally understood to be immune-mediated, with the binding of auto-reactive antibodies to the GP IIb/IIIa platelet receptor. Complexes formed between platelets and these auto-antibodies bind to the $\mathrm{Fc}$ receptors of macrophages and are eliminated from systemic circulation. Inciting events may include viral upper respiratory infection, hepatitis $\mathrm{C}$, HIV or medications. Although most patients remain asymptomatic, some may present with petechiae, easy bleeding and bruising. Those with extremely low platelet count may present with wet purpura or bullae in the oral mucosa that are tenuous and have the potential for bleeding. Initial workup should include a comprehensive history and physical examination. A peripheral blood smear should be evaluated for the presence of blasts, schistocytes or platelets clumping (suggestive of pseudo-thrombocytopenia). Laboratory analysis to rule out any deficiencies in vitamin $B_{12}$ or folate, or antecedent viral infections like hepatitis $\mathrm{C}$ and HIV should also be undertaken. Initial therapy for ITP, as in the presented case, revolves around the administration of high-dose dexamethasone at $40 \mathrm{mg}$ oral daily for 4 consecutive days. ${ }^{2} 3$ Addition of intravenous immunoglobulin or IVIG, which is administered at $1 \mathrm{~g} / \mathrm{kg}$ for 1 to 2 days $^{3}$ can be considered in patients with extremely low platelet count of $5-10 \times 10^{9} / \mathrm{L}$ or active bleeding with platelet count $<30 \times 10^{9} / \mathrm{L}$.

Initial treatment for ITP largely revolves around corticosteroids in the form of prednisone $(1 \mathrm{mg} / \mathrm{kg} / \mathrm{day})$, high-dose dexamethasone ( $40 \mathrm{mg}$ for 4 consecutive days) or high-dose solumedrol (250-1000 mg/day). The existing therapies for ITP not responding to corticosteroids are best thought of in distinct categories, which broadly include splenectomy, rituximab, thrombopoietin receptor agonists (TPO-RAs) and anecdotal therapies.

Rituximab dosing in ITP is often $375 \mathrm{mg} / \mathrm{m}^{2}$ weekly for 4 weeks, but $1000 \mathrm{mg}$ every twoweeks with two doses has shown similar rates of response, which is approximately $60 \%$ (ie, maintenance of a normal platelet count $>150 \times 10^{9} / \mathrm{L}$, with $20 \%-40 \%$ of patients staying in long-term remission. Time of onset of action is anywhere from 1 to 8 weeks. Hence, rituximab is not an ideal option when rapid improvement in platelet count is needed. Based on results of a systematic review published in 2007, the median time to achieve normalisation of platelet count was 5.5 weeks, ${ }^{2}$ making rituximab a poor choice in acute ITP where there is an impending risk of life-threatening bleeding. Adverse effects of rituximab vary, but generally include infusion reaction (grade III/IV in up to $2 \%$ of patients) and reactivation of chronic hepatitis B. Patients receiving rituximab, therefore, should also undergo screening for viral hepatitis prior to administration of the drug. ${ }^{1}$

Splenectomy has also been utilised in ITP cases that are either unresponsive or have relapsed after use of corticosteroids. A 2014 case series consisting of 72 such patients with ITP who had undergone splenectomy revealed promising results with response seen in $87.5 \%$ of patients, and a majority lasting for a long period of time. Thrombosis was a common adverse event, occurring in $8.3 \%$ of patients, and included deep vein thrombosis and pulmonary embolism. ${ }^{4}$

TPO-RAs were not used in the presented case, but they have established utility in managing ITP, both as rescue and maintenance therapy. Using romiplostim at $3 \mu \mathrm{g} / \mathrm{kg} /$ week, an initial response in the platelet count $\geq 50 \times 10^{9} / \mathrm{L}$ has been observed at a median of 2 weeks in patients with ITP, including both splenectomised and non-splenectomised patients. The time to discontinuation of 


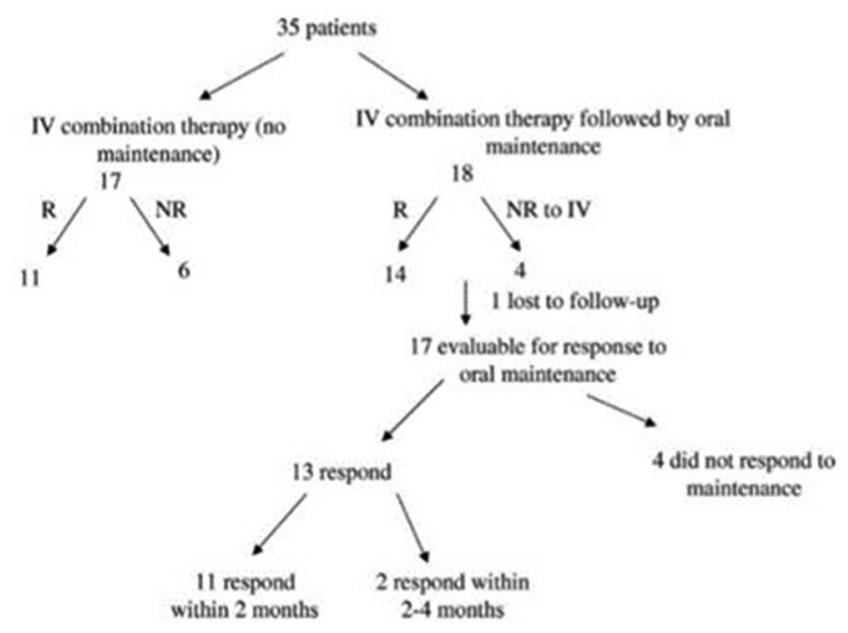

Figure 2 Schema for Boruchov et al study, with results by treatment combination. NR, no response; $R$, response. ${ }^{6}$

therapy was variable. Patients who underwent splenectomy were weaned off treatment at a median of 72 weeks whereas, patients who did not undergo splenectomy were able to successfully discontinue therapy at 20 weeks. ${ }^{5}$ On comparing TPO-RAs, one recently published retrospective series examined 100 patients with either newly-diagnosed, persistent or chronic ITP, of which 37 received romiplostim, 41 received eltrombopag and 22 received both therapies. While no difference was noted in response rate between these individual TPO-RAs, the rate of maintaining a response when TPO-RA was discontinued was $25 \%$ in patients with persistent or newly-diagnosed ITP and 7.2\% in those with chronic disease. ${ }^{6}$ Romiplostim has been associated bone marrow reticulin fibrosis in as many as $5.6 \%$ of patients, leading to anaemia, as well as thrombosis in $8 \%-10 \%$ of patients over 100 patient weeks. Eltrombopag has been associated with elevation of liver enzymes in 3\%-7\% of patients. ${ }^{1}$

Anecdotal therapies are also relevant to the discussion of this case. Our patient had severe symptomatic thrombocytopenia with platelet counts $<10 \times 10^{9} / \mathrm{L}$ that did not respond to the conventional combination of steroids and IVIG followed by rituximab, but did respond to the addition of vincristine with an improved platelet count of $>50 \times 10^{9} / \mathrm{L}$. Based on literature review, vincristine has been associated with an overall response rate of 50\%-63\% in patients with ITP not responsive to corticosteroids and/or IVIG. ${ }^{1}$ Regarding the role of vincristine for shortonset improvement in platelet count, Boruchov et al in 2017 reported a study comprising 35 patients with ITP that had been refractory to previous therapy with high-dose steroids or IVIG. Patients were administered one of two regimens: a combination of either 3 or 4 drugs, which at minimum included steroid and IVIG with added anti-D or vincristine or both (schema shown in figure 2). In total, $71 \%$ of patients responded to combination therapy with a platelet increase of, at minimum, $20 \times 10^{9} / \mathrm{L}$ to a level of $\geq 30 \times 10^{9} / \mathrm{L}$. As reported in the study, the mean platelet count prior to the initiation of combination therapy was $12 \times 10^{3} / \mu \mathrm{L}$. By days $2-5$ of therapy, this value was $68 \times 10^{9} / \mathrm{L}$ and $111 \times 10^{9} / \mathrm{L}$ by days $6-10$. From days $11-17$, median platelet count was sustained at $>35 \times 10^{3} / \mu \mathrm{L}$. The study concluded that combination therapy with intravenous IV steroids, immunoglobulin and/or anti-D and vinca alkaloids was a viable option for achieving rapid rise in platelet count in patients with ITP after inadequate response to first line therapy. ${ }^{7}$
Learning points

- Severe idiopathic thrombocytopenic purpura (ITP), with platelet count $<10 \times 10^{9} / \mathrm{L}$ or with active bleeding, can be managed effectively in the inpatient setting with a multifaceted approach that includes, but is not limited to, supportive platelet transfusion, high-dose steroids or intravenous immunoglobulin.

- ITP that is not responsive to the aforementioned conventional therapies can be treated with other treatment modalities, which broadly include monoclonal antibodies such as rituximab, thrombopoietin receptor agonists (TPO-RAs) and anecdotal therapies such as vinca alkaloid.

- Rituximab is effective as therapy in ITP, but the median time to achieving platelet normalisation is 5.5 weeks, making it a poor choice for patients with severe or life-threatening bleeding.

- TPO-RAs have demonstrated success in patients who have or have not undergone splenectomy, although those who have not had the surgery are able to discontinue therapy sooner (median 20 weeks) than those who have (median 72 weeks).

- Combining vinca alkaloids with intravenous steroids, immunoglobulin and/or anti-D is an effective approach to enacting a rapid increase in platelet count for patients with ITP.

Contributors SBR, as the primary author of this manuscript, had a large role in writing the manuscript, specifically in acquiring data from the most relevant studies and incorporating such data into the manuscript to support and/or refute our arguments in to be as objective as possible. $\mathrm{HH}$ played an important role in the conception, design and construction of this manuscript, including selecting which content to highlight, use of proper research language. He also played a small role in data interpretation. PN played a major role in writing the manuscript, particularly the case section, and in interpreting data that would be presented in figures. She also had a role in manuscript design. GK played a supervisory role as the project's principal investigator, and oversaw the interpretation and analysis of collected data. He was also essential in connecting the current literature to our own patient's case, which resulted in effective translational care for the patient and for communication of ideas and learning through the manuscript.

Funding The authors have not declared a specific this research from any funding agency in the public, commercial or not-for-profit sectors.

Competing interests None declared.

Patient consent for publication Obtained.

Provenance and peer review Not commissioned; externally peer reviewed.

\section{REFERENCES}

1 DeLoughery TG. Clinical review - immune thrombocytopenia. Hospital Physician; Hematology-Oncology Board Review Manual 2017;12:35-48.

2 Cheng Y, Wong RSM, Soo YOY, et al. Initial treatment of immune thrombocytopenic purpura with high-dose dexamethasone. N Engl J Med Overseas Ed 2003;349:831-6.

3 Khan AM, Mydra H, Nevarez A. Clinical practice updates in the management of immune thrombocytopenia. P T 2017; 42:756-63.

4 Rijcken E, Mees ST, Bisping G, et al. Laparoscopic splenectomy for medically refractory immune thrombocytopenia (ITP): a retrospective cohort study on longtime response predicting factors based on consensus criteria. Int J Surg 2014;12:1428-33.

5 Mingot-Castellano ME, Grande-García C, Valcárcel-Ferreiras D, et al. Sustained remission in patients with primary immune thrombocytopenia after romiplostim tapering and discontinuation: a case series in real life management in Spain. Case Rep Hematol 2017;2017:1-8.

6 Mingot-Castellano ME, Caparrós IS, Fernández F, et al. Treatment characteristics, efficacy and safety of thrombopoietin analogues in routine management of primary immune thrombocytopenia. Blood Coagulation \& Fibrinolysis 2018;29:374-80.

7 Boruchov DM, Gururangan S, Driscoll MC, et al. Multiagent induction and maintenance therapy for patients with refractory immune thrombocytopenic purpura (ITP). Blood 2017; 110:3526-31 
Copyright 2018 BMJ Publishing Group. All rights reserved. For permission to reuse any of this content visit https://www.bmj.com/company/products-services/rights-and-licensing/permissions/

BMJ Case Report Fellows may re-use this article for personal use and teaching without any further permission.

Become a Fellow of BMJ Case Reports today and you can:

- Submit as many cases as you like

- Enjoy fast sympathetic peer review and rapid publication of accepted articles

Access all the published articles

- Re-use any of the published material for personal use and teaching without further permission

For information on Institutional Fellowships contact consortiasales@bmjgroup.com

Visit casereports.bmj.com for more articles like this and to become a Fellow 